\title{
"A grande Argentina": um sonho nacionalista para a construção de uma potência na América Latina*
}

José Luis Bendicho Beired ${ }^{* *}$

UNESP-Assis

\section{RESUMO}

Visa-se analisar a proposta de transformação da Argentina em uma potência econômica e militar hegemônica na América do Sul, levada a cabo por correntes de extrema-direita desse país, entre as duas Guerras Mundiais. Discutem-se os objetivos, conteúdos e fundamentação dessa proposta no contexto do cenário internacional e da conjuntura política argentina.

Palavras-chave: Argentina; nacionalismo; direita.

\section{ABSTRACT}

This article deals with the right wing projects, between the two World Wars that intended the transformation of Argentina into the most influent and powerful country in South America. We will discuss the goals and the fundamentation of these proposals relating them with the international scene and the Argentine political conjuncture.

Keywords: Argentine; nationalism; right wing.

A partir da década de 1920, uma nova corrente de direita mobilizou-se na Argentina em torno de uma série de bandeiras, que incluíram a proposta de transformar esse país em uma potência econômica, militar e imperialista. Constituída majoritariamente por intelectuais oriundos das tradicionais classes dirigentes, essa corrente interveio na vida pública por meio da organização de associações políticas, de ligas militarizadas, da publicação de jornais, revistas e livros, e em aliança com setores políticos, da Igreja Católica e das forças armadas. Aqui denominada como "nacionalismo de direita" ou "direita nacionalista", essa corrente política e ideológica arquitetou um conjunto de representações que contribuiu para forjar uma nova cultura política ${ }^{1} \mathrm{em}$ parcelas significativas da sociedade e dos responsáveis pelas instituições argentinas, notadamente os militares.

A presença de uma proposta imperialista no seio da direita nacionalista argentina tem sido desconsiderada ou no mínimo negligenciada pelos historiado- 
res. Os estudos feitos na óptica do nacionalismo omitem essa presença, o que é compreensível como estratégia de construção de uma memória simpática à experiência argentina de extrema-direita ${ }^{2}$. Em outra categoria de trabalhos, mais rigorosos em termos teórico-metodológicos e não identificados ideologicamente com essa direita, vale mencionar a posição de dois autores importantes. Segundo Cristián Buchrucker, a comparação do fascismo europeu com o nacionalismo de direita argentino sugere que neste faltou o "expansionismo militar" e a propaganda do "espaço vital" historiador David Rock afirmou, sem se aprofundar, que certas idéias dos nacionalistas "insinuavam fortes tendências imperialistas e expansionistas", referindo-se à rememoração e exaltação do Vice-Reinado do Rio da Prata, que compreendia o Uruguai, o Paraguai e a Bolívia ${ }^{4}$. As nossas pesquisas sobre a direita nacionalista argentina apontam na direção assinalada por David Rock. Consideramos que há evidências de que efetivamente os intelectuais nacionalistas propuseram para a Argentina o papel de potência econômica, militar e imperialista, o que buscaremos examinar com maiores detalhes ao longo deste artigo.

As inúmeras publicações da direita nacionalista constituíram lugares privilegiados para a difusão da sua ideologia política ${ }^{5}$ e são, portanto, fonte inestimável para o estudo da sua produção ideológica e das suas práticas políticas. Recorrendo a uma seleção dessas fontes, a seguir abordaremos a fundamentação da proposta imperialista no contexto do conjunto de representações da direita nacionalista. Ao mesmo tempo, buscaremos explicar como as situações apresentadas pela conjuntura política nacional e internacional influenciaram na elaboração da alternativa imperialista, fazendo com que a sua concretização pudesse se tornar plausível.

A direita nacionalista representou uma ruptura com o modelo de direita até então vigente na Argentina, ao assumir posições veementemente antiliberais, nacionalistas, estatistas, corporativistas, católicas e anti-semitas. À diferença da direita preexistente - liberal ou conservadora — , recusava de modo integral os princípios e as instituições liberais. Com uma visão antiiluminista e condenatória dos efeitos da modernização, essa direita sustentava a manutenção das tradições nacionais e abraçava princípios antiliberais e antiigualitários, uma vez que liberdade e igualdade eram consideradas abstrações que deveriam ser substituídas por outros valores assentados nas noções de autoridade, ordem, hierarquia e obediência. 0 liberalismo deveria ser substituído por uma "verdadeira ideologia nacional", de modo a superar-se a incongruência entre a realidade nacional e o "artificialismo" das instituições liberais.

A solução da crise argentina dependia da construção daquilo que os intelectuais denominavam "nova ordem". Os significados da "nova ordem" dependeram dos diagnósticos da crise elaborados pelas diferentes correntes naciona- 
listas, o que explica que o programa de alternativas para superar os problemas nacionais não fosse unívoco. 0 programa nacionalista autoritário desenvolveu um conjunto de alternativas, tais como: a constituição de um Estado corporativista e autoritário; o nacionalismo econômico, a industrialização e o intervencionismo estatal na economia; a reespiritualização da sociedade e do Estado por meio do catolicismo; e a adoção de uma postura imperialista na América do Sul.

A direita nacionalista estruturou-se como corrente no final da década de 1920, em torno da luta contra o governo da União Cívica Radical presidido por Hipólito Yrigoyen $(1928-1930)^{6}$, tendo no jornal La Nueva República, na revista católica Criterio e na Liga Republicana seus primeiros e decisivos espaços de organização, que se desdobraram em muitos outros no decorrer dos anos seguintes ${ }^{7}$. Em vista da sua total reprovação aos partidos políticos e ao sistema representativo - entendidos como males demagógicos criados pelo liberalismo — os nacionalistas recusaram-se a se organizar partidariamente. Fizeram das suas dezenas de agrupações e publicações as suas principais trincheiras de combate pela construção de uma "nova ordem", que restaurasse o país daquilo que consideravam ser um longo ciclo de decadência histórica e de corrupção dos valores fundamentais da nação argentina. Os intelectuais nacionalistas investiram-se da missão de salvar a nação contra o que julgavam ser uma vasta conspiração de forças inimigas da Argentina, cuja encarnação eram: as finanças internacionais, a democracia, o liberalismo, o bolchevismo, os partidos políticos, o movimento operário, os imigrantes, e em particular os judeus. Juntos minavam a nacionalidade e seus pilares: o passado glorioso, a tradição hispânica, o catolicismo, a família e valores, tais como ordem, hierarquia autoridade, disciplina e heroísmo, enfim, valores inerentes a uma concepção autoritária da identidade nacional ${ }^{8}$.

Os intelectuais nacionalistas acreditavam ser o único segmento social capaz de oferecer respostas às elites dirigentes nacionais, que consideravam alienadas, e de imprimir uma direção política coerente à nação. Eles compartilhavam o diagnóstico de que a Argentina passava por uma profunda crise, cuja solução dependia da articulação entre as transformações internas e aquelas que configuravam uma nova ordem mundial. Dentre os principais expoentes da direita nacionalista vale destacar: Ernesto Palácio, os irmãos Julio e Rodolfo Irazusta, Leopoldo Lugones, Julio Meinvielle, Leonardo Castellani, Marcelo Sánchez Sorondo e Carlos Ibarguren. A intensa atividade desses intelectuais autoritários permite afirmar que conformaram um campo ideológico e intelectual específi$\mathrm{CO}^{9}$, a direita nacionalista, disposto a disputar a hegemonia com as outras forças ideológicas, políticas e culturais. Entretanto, apesar de possuírem inúmeras posições em comum, a direita nacionalista encontrava-se dividida em correntes. A direita argentina organizou-se em torno de dois grandes pólos ideológicos: fas- 
cista e católico, entre os quais distribuía-se o conjunto dos intelectuais. Certos intelectuais situavam-se em posições coincidentes com um dos pólos constituintes do campo, como por exemplo o poeta argentino Leopoldo Lugones, claramente fascista, ou Júlio Meinvielle, de postura católica; outros ainda apresentavam posições que buscavam um compromisso entre o fascismo e o catolicismo. Era o caso dos intelectuais reunidos em torno dos jornais Nueva República e das revistas Nuevo Orden e Nueva Política, como por exemplo os irmãos Irazusta, Ernesto Palácio e Marcelo Sanchez Sorondo.

Na percepção dos nacionalistas, a Argentina encontrava-se oprimida externamente por uma situação de dependência econômica com relação à Grã-Bretanha, e de inferioridade galopante diante da projeção econômica, militar e diplomática do Brasil. Embora essa percepção fosse baseada em fatos concretos, ela foi filtrada pela cultura de direita em voga no mundo e pela adoção de uma posição defensiva da direita argentina perante as mudanças que vinham ocorrendo. Deve-se acrescentar que um dos elementos importantes que atuaram na filtragem dos acontecimentos pelos nacionalistas foi justamente 0 anti-semitismo, e a crença de que os judeus moviam uma conspiração internacional destinada a dominar economicamente a Argentina e a solapar a suas bases políticas e sociais. Além disso, para os nacionalistas a Primeira Guerra abrira uma nova era repleta de promessas, pois não só representava a derrota do liberalismo como também atestava a decadência dos valores que tinham pautado a sociedade ocidental desde os tempos "áureos" da Idade Média ${ }^{10}$. 0 sepultamento da era liberal pela Primeira Guerra descortinava um novo cenário pautado pela emergência de uma "nova ordem" de natureza autoritária, legitimando as estratégias de uso da força militar tanto no âmbito interno quanto entre as nações. As questões relativas à decadência da civilização ocidental e ao surgimento de uma nova ordem foram intensamente debatidas nos anos seguintes à Primeira Guerra. Alguns intelectuais foram centrais nesse debate: o líder da Ação Francesa, Charles Maurras, o filósofo alemão Oswald Spengler, o filósofo russo Nicolai Berdiaeff, o escritor católico francês Hilaire Belloc, e o escritor e jornalista espanhol Ramiro de Maeztu. Para todos esses autores, o presente mostrava-se como uma fase da história inferior a certos momentos do passado em razão de diversos motivos: ascensão do materialismo, declínio da religião e dos valores espirituais, democratização do poder político, difusão do liberalismo, do socialismo e do comunismo, e influência maléfica dos judeus. 0 declínio somente seria revertido mediante a criação de uma nova ordem que suprimisse as fontes de corrosão da sociedade e restaurasse valores e princípios de ordem social de natureza hierárquica. Daí, a defesa feita por Berdiaeff de retorno à Idade Média, idealizada como Idade de Ouro.

As novas perspectivas propaladas pelos nacionalistas encontraram uma 
rápida e profunda acolhida nas forças armadas, selando uma relação duradoura entre ambos os segmentos. 0 primeiro grande momento dessa convergência deu-se por ocasião do golpe militar contra o governo radical, em setembro de 1930, que levou ao poder o general José Félix Uriburu. Arquitetado com a participação dos militantes da Liga Republicana ${ }^{11}$, o golpe significou a vitória dos setores antiliberais e nacionalistas das forças armadas, inaugurando um longo ciclo de participação dos militares na vida pública do país. Em 1931, o gal. Uriburu criou a Legião Cívica Argentina, organização militarizada de caráter fascista voltada a arregimentar simpatizantes nacionalistas em apoio ao novo regime militar e a combater os seus inimigos. Dirigida por membros do alto escalão das forças armadas, a legião era integrada por brigadas de homens, mulheres e crianças, sempre prestes a participar de manifestações cívicas oficiais, tais como o primeiro aniversário do golpe de setembro de 1930, quando desfilaram 150 brigadas provenientes do país inteiro pelas ruas da capital federa ${ }^{12}$.

0 projeto uriburista de implantação de uma república corporativista fracassou dando lugar à convocação de eleições — tuteladas, restritivas e fraudulentas - em 1931 e 1937. Apesar disso, a aliança entre nacionalistas e setores militares manteve-se estável ao longo dos anos trinta, observando-se uma importante participação de militares nas organizações nacionalistas ${ }^{13}$. As relações entre militares e nacionalistas ganharam novo impulso a partir do início da Segunda Guerra. 0 conflito descortinou um cenário de rearranjo do sistema de relações internacionais, em que a vitória do Eixo foi vislumbrada como um fator decisivo para conduzir uma aliança de extrema direita à direção da Argentina, e ao mesmo tempo projetar geopoliticamente o país na América Latina.

\section{DA CRÍTICA AO PACIFISMO AO PROJETO DA ARGENTINA COMO POTÊNCIA ECONÔMICA E MILITAR}

0 avanço do nacionalismo na década de 1920 foi acompanhado pelo crescimento das idéias belicistas na Argentina. Foi nessa época que o escritor e poeta Leopoldo Lugones, um dos principais líderes do nacionalismo de direita, abandonou suas posições liberais, o internacionalismo e o pacifismo, passando a professar o darwinismo social, o império da irracionalidade, da força e da vontade na vida social. Dessa maneira, Lugones destacou-se como a primeira grande figura pública argentina a desenvolver uma acirrada crítica ao pacifismo, a qual foi completamente assimilada pela direita nacionalista.

Lugones definia o gênero humano como intrinsecamente feroz, à semelhança dos animais carnívoros, e afirmava que a guerra constituía uma função vital para o homem, resultante da sua índole conquistadora e agressiva ${ }^{14}$. A Primeira 
Guerra desempenhara um papel essencial para essa guinada ideológica, que de resto foi acompanhada por amplos setores da intelectualidade ocidental. Para Lugones, a guerra demonstrara a falência dos valores humanistas do iluminismo e a preponderância dos interesses nacionais nas relações externas. Nos conflitos entre os países, venciam aqueles mais fortes, aqueles capazes de desempenhar da melhor forma as virtudes militares. 0 seu famoso "Discurso de Ayacucho" ficou consagrado pela simultânea condenação do pacifismo e pela exaltação do novo tempo inaugurado pela guerra de 1914, "a hora da espada"15.

Rodolfo Irazusta, outra figura central da direita nacionalista da época, também condenou o pacifismo propalado pelas nações vitoriosas na Primeira Guerra no famoso jornal La Nueva República, expressando uma perspectiva compartilhada pelo conjunto dos nacionalistas. 0 pacifismo seria uma teoria somente abraçada pelos povos sem vontade de viver, e a paz, o resultado da força bem administrada para o bem das nações mais poderosas. Entendendo que a Argentina era uma vítima do pacifismo liberal, fomentado e instrumentalizado pela dominação britânica, Rodolfo Irazusta também denunciava os perigos do socialismo e do sistema financeiro internacional, ambos tidos como instrumentos de uma conspiração judaica para desarmar os povos latinos e avançar na dominação do mundo ${ }^{16}$. A temática conspiratória, aliás, não era um aspecto de pouca monta no ideário do nacionalismo de direita, podendo-se afirmar que uma certa teoria conspirativa da história não somente foi como ainda é um dos seus componentes centrais, sistematizado naquilo que ficou conhecido como "revisionismo histórico" de direita ${ }^{17}$.

As idéias antipacifistas dos nacionalistas foram desenvolvidas de modo entrelaçado à defesa da transformação da Argentina em uma potência econômica e militar à altura das mais importantes do planeta. Leopoldo Lugones foi pioneiro entre os nacionalistas ao defender a conversão da Argentina em uma economia industrializada, assentada no mercado interno e independente de outros países. Tais idéias foram apresentadas no livro $\mathrm{La}$ Grande Argentina, produto de sua reflexão e trabalho jornalístico durante os anos vinte ${ }^{18}$. Ali definia o país como uma "república rural", situada num "estado colonial" com relação às nações industrializadas. Estas eram encaradas como uma ameaça à soberania argentina, na medida em que tendiam a agir de forma imperialista — armada ou não - sobre aqueles produtores de matérias-primas ${ }^{19}$. No contexto posterior à Primeira Guerra, percebeu que o país não teria condições nem de financiar suas importações e nem de crescer devido às políticas protecionistas adotadas pelos países europeus com relação aos produtos primários. Assim, o segredo da prosperidade não residia no comércio exterior, mas antes no mercado interno. Para tanto, o país necessitava possuir certos ramos industriais vitais, que processassem as matérias-primas produzidas internamente: siderurgia, eletricidade, cons- 
trução, combustíveis, transporte, implementos agrícolas, vestuário, higiene e alimentação ${ }^{20}$.

Compartilhando a crítica lugoniana, os irmãos Irazusta desempenharam um papel essencial no campo nacionalista ao construir uma teoria para explicar a situação de dependência da Argentina em face do exterior. Essa teoria, que teve uma acolhida unânime entre os nacionalistas, foi primeiramente desenvolvida nas páginas de La Nueva República, mas sua consagração apenas ocorreu com a publicação de um livro que se tornou um marco do chamado "revisionismo histórico" argentino: La Argentina y el Imperialismo Británico, publicado em $1934^{21}$. O livro considerava que os interesses econômicos e diplomáticos britânicos, com o apoio de setores liberais da sociedade argentina - definidos pelos autores como "oligarquia" - mantinham a Argentina em uma situação neocolonial, condenando-a a ter uma economia primária, e impedindo a sua diversificação e industrialização. De fato, a dependência da Argentina em relação à GrãBretanha, existente desde o século XIX, ganhou novas proporções a partir de 1933, com a assinatura do Tratado Roca-Runciman, acordo comercial que estipulou normas relacionadas às exportações de carnes argentinas para a Grã-Bretanha e de importações de produtos britânicos pela Argentina. Para muitos, as cláusulas do tratado colocaram o país platino em uma posição comercial desvantajosa diante dos britânicos, abrindo-se uma polêmica na qual os irmãos Irazusta e os demais nacionalistas que os apoiaram se apresentaram aos argentinos como defensores dos interesses nacionais. De acordo com o livro, o tratado só reforçava a tese de que a "oligarquia liberal" argentina sempre fora movida por interesses inconfessáveis que traíam o conjunto do país. De uma maneira maniqueísta que se tornou praxe nos ambientes nacionalistas, os autores dividiam o país em dois lados, um bem intencionado e patriota, e outro imoral e antiargentino, no qual encaixavam-se todos os seus inimigos.

Ao longo dos anos trinta os nacionalistas aprofundaram os seus ataques aos inimigos externos da Argentina e difundiram a imagem da hidra tricefálica que devoraria a nação: os britânicos, os judeus e o fantasma comunista. Com a eclosão da Segunda Guerra vislumbraram a possibilidade de libertar a Argentina da sua situação neocolonial na medida em que estava em jogo todo o sistema de relações internacionais. Nesse sentido, Júlio Irazusta considerava que:

As regiões excêntricas do mundo poderão desfrutar no futuro de uma autonomia, de uma independência efetivas [...]. 0 momento é providencial. Se o aproveitarmos agora, poderemos conseguir o cumprimento definitivo da empresa libertadora começada faz 130 anos. ${ }^{22}$

Nesse novo contexto, os nacionalistas passaram a reivindicar uma indus- 
trialização mais intensa, com a implantação das indústrias de base, consideradas necessárias para a independência econômica do país e para o desenvolvimento de seu arsenal bélico ${ }^{23}$. A defesa de tais atividades econômicas também expressava a convergência do nacionalismo de direita com os interesses estratégicos das forças armadas argentinas. Desde o início da década de 1930, o exército viu-se afetado pelas mudanças técnicas em relação aos equipamentos militares e pelas novas formas de mobilização postas em prática nas duas guerras mundiais. Os militares entendiam que o escasso desenvolvimento industrial da Argentina limitava a capacidade técnica do exército, e por isso passaram a defender políticas industrialistas. Assim, na década de 1940, o exército desenvolveu programas de renovação tecnológica voltados para a produção dos equipamentos militares considerados necessários, afetando assim a própria atividade econômica do país na medida em que estimulou o desenvolvimento de setores da indústria ${ }^{24}$.

A Segunda Guerra, junto com a ascensão da extrema direita em escala internacional, contribuiu sobremaneira para dar um novo alento ao nacionalismo de direita. Os seus militantes argentinos acreditaram que a sua hora de chegar ao poder finalmente estava em vias de se concretizar. Com o apoio de setores importantes das forças armadas, retomaram com inusitado vigor as suas teses militaristas e lhes adicionaram ingredientes que contrariavam frontalmente a política externa dos Estados Unidos para a América Latina. A atuação dos nacionalistas em termos de propaganda e sua articulação não só com as forças armadas, mas também com membros do clero e o aparelho do Estado foram sem dúvida fatores essenciais para que os Estados Unidos vissem na Argentina a principal base de apoio ao Eixo na América Latina, produzindo uma contínua tensão nas relações entre esses dois países ${ }^{25}$.

\section{IMPERIALISMO, MILITARISMO E POLÍTICA INTERNACIONAL}

A hipótese de que a direção política da Argentina deveria ser assumida pelos militares foi desenvolvida pela direita nacionalista a partir dos anos vinte, quando foram considerados por Lugones como a "última aristocracia" que restava ao país. Desde então os nacionalistas passaram a exaltar as virtudes típicas dos militares, tais como hierarquia, obediência, ordem, disciplina, tradição e heroísmo, as quais eram ademais reconhecidas como os atributos definidores do caráter hispânico e, por extensão, do caráter nacional argentino.

Ao lado da apologia da guerra e dos regimes de força, o imperialismo foi outro aspecto já presente no discurso nacionalista dos anos vinte potenciado pela Segunda Guerra. Lugones foi uma vez mais um exemplo fundamental para 
os nacionalistas de direita ao defender as práticas imperialistas - no sentido de expansão territorial do Estado e da imposição dos interesses argentinos sobre outros países - como meio de satisfazer as "necessidades vitais" para a transformação do seu país na "Grande Argentina”. Assim considerava naturais as guerras entre países poderosos e débeis, pois representava a condição necessária para o desenvolvimento dos mais fortes:

(...) o crescimento da potência é acompanhado pelo da necessidade, dado que a primeira consiste essencialmente no aumento da população e no progresso industrial que requer cada vez maior quantidade e variedade de matéria-prima. (...) toda exigência natural de conservação, unida à capacidade de satisfazê-la pela força, torna o poder em querer, segundo ensina a história sem exceção. Potência e conquista, ou imperialismo como dizemos atualmente, são termos correlatos.(... $)^{26}$

A ênfase que conferimos a Lugones como ideólogo da direita nacionalista argentina justifica-se por entendermos que ele introduziu certas interpretações que seriam exaustivamente retomadas por essa corrente nos anos trinta e principalmente durante a Segunda Guerra. Ou seja, a nossa hipótese é de que as teses belicistas e imperialistas do nacionalismo argentino não decorrem desse conflito, mas têm origem na crise ideológica desatada pela Primeira Guerra. Lugones expressa claramente uma posição similar à adotada pelos fascismos europeus para justificar o expansionismo e reflete o que poderíamos chamar de uma "sensibilidade fascista", que perpassava as representações dos extremistas de direita do mundo ocidental a partir dos anos vinte.

0 círculo de intelectuais que atuou na revista Nueva Política foi um dos que defenderam com mais empenho o retorno dos militares ao poder para a realização de uma "revolução nacional", que assumisse entre outras tarefas: reordenar internamente o país de forma autoritária de modo a liquidar o "perigo vermelho" e os restos de liberalismo; e transformar a Argentina numa potência econômico-militar hegemônica na América do Sul, aproveitando as profundas transformações da geopolítica internacional suscitadas pela Segunda Guerra.

Com uma argumentação tipicamente fascista, a revista chegou a fazer a defesa do imperialismo militar da Argentina sobre os países latino-americanos em nome do dever e do direito de proteção da nação, definida como um organismo vivo. Nueva Política sustentava que a nação, enquanto ser vivo, crescia, procriava e estendia-se no tempo e no espaço, assimilando outras nações menos vigorosas. A revista também acrescentava que o direito de conquista era legítimo se atendesse a certos pré-requisitos, tais como: responder a uma necessidade vital do povo conquistador; que não significasse a escravidão do conquistado, mas ao contrário, a sua "civilização"; e que a outra nacionalidade 
não fosse destruída. Ademais, alegava-se que os povos superiores tinham a obrigação de civilizar os inferiores, como haviam feito os países europeus em relação à África. Evidencia-se, portanto, que os nacionalistas sustentavam a superioridade argentina e seu direito de conquista por meio de argumentos equivalentes àqueles contidos no discurso expansionista da Itália e da Alemanha fascistas ${ }^{27}$.

0 posicionamento dos nacionalistas diante do problema geopolítico foi um elemento importante no ambiente de competição entre a Argentina e o Brasil, vigente nos anos trinta e quarenta pela hegemonia na América do Sul, e principalmente na Bacia do Prata. Os artigos e editoriais da revista revelavam enorme preocupação com a aproximação entre o Brasil e os Estados Unidos durante a Segunda Guerra ${ }^{28}$. Contra o que afirmavam ser uma política expansionista e hegemônica do Brasil, reclamavam iniciativas governamentais que colocassem a Argentina em uma clara posição de superioridade com relação ao seu maior vizinho. A vitória do Eixo, almejada desde o início da guerra, tornou-se ainda mais imperativa com o apoio do governo de Getúlio Vargas aos Aliados, uma vez que a vitória destes resolveria de vez a disputa geopolítica na América do Sul em favor do Brasil. A respeito da rivalidade com o Brasil, considerava-se que:

(...) é inevitável e somente poderá acabar no dia em que a Argentina ocupe, de forma decisiva, o papel que lhe corresponde de potência dirigente no continente sulamericano $^{29}$.

Considerava-se que o primeiro objetivo da política exterior argentina deveria ser o acréscimo de influência do país no subcontinente, com vistas a transformá-la na principal potência da região. A partir dessa posição ambicionavase inclusive que a Argentina pudesse estender sua influência para outras regiões além da América Latina ${ }^{30}$. Mas antes disso, tornava-se fundamental o controle da margem uruguaia do Rio da Prata, conforme as palavras de um nacionalista, ao analisar as relações entre o Brasil e a Argentina:

O desenvolvimento de uma grande potência, como pode vir a ser a Argentina, exige a proteção dos seus pontos vitais. Buenos Aires, colocada a poucos minutos do território estrangeiro, carece das condições estratégicas ideais, (...). Daí a necessidade de dominar toda a bacia, e em particular ambas as margens da desembocadura do Prata, como uma prenda da sua expansão política. ${ }^{31}$

Evidentemente a posição dos nacionalistas, que era compartilhada por numerosos e importantes segmentos do exército argentino, colidia frontalmente com a política pan-americanista desenvolvida por Washington, e por isso mes- 
mo teve o apoio da Alemanha nazista, que por meio de sua embaixada em Buenos Aires financiou as atividades de certos grupos nacionalistas. Um dos casos mais notórios foi o financiamento do diário Pampero, publicado na capital do país a partir de 1940, que fazia a apologia dos nazistas durante a Segunda Guerra.

"Buenos Aires, cabeça do sexto continente" foi a expressão cunhada por Marcelo Sanchez Sorondo para definir a liderança que a Argentina deveria exercer na América Espanhola, em contraposição aos interesses norte-americanos na região $0^{32}$. Esse intelectual nacionalista argumentava que as peculiaridades religiosas, idiomáticas, culturais, históricas e raciais dos países abaixo do rio Grande conferiam a essa vasta região uma sólida unidade, completamente diferente e incompatível com os Estados Unidos. Por isso a América Latina constituía-se em um continente à parte, cuja alma, modo de ser e de pensar, tinham em Buenos Aires o principal representante. Esse juízo era, entre outras coisas, uma exaltação da vitória obtida pela Argentina na Conferência do Rio de Janeiro, realizada em janeiro de 1942. Essa reunião cujo objetivo era assegurar a solidariedade continental ante a agressão militar japonesa aos Estados Unidos, assim como conquistar a ruptura coletiva de relações com os países do Eixo, foi um completo malogro para a diplomacia norte-americana, e pôs em cheque o sistema panamericano. 0 chanceler argentino Enrique Ruiz Guiñazú foi à conferência com ordens expressas do vice-presidente em exercício, Ramón Castillo, de não renunciar de nenhuma maneira à posição de neutralidade. Ruiz Guiñazu conseguiu negociar com o delegado norte-americano Summer Welles uma resolução intermediária que apenas "recomendava" aos países americanos a ruptura de relações com o Eixo. Tal decisão desobrigou a Argentina de alterar sua posição internacional de neutralidade e significou uma importante derrota para os Estados Unidos ${ }^{33}$.

Utilizando jornais, revistas e manifestações públicas, os nacionalistas de direita lideraram uma ostensiva posição de ataque à política pan-americanista desenvolvida pela diplomacia norte-americana durante a Segunda Guerra. Grande parte dos esforços dos nacionalistas dirigiu-se exatamente no sentido de criar um movimento de opinião pública favorável à manutenção da neutralidade da Argentina, contribuindo assim para fortalecer não apenas a postura neutra do governo de Ramón Castillo, mas sobretudo os setores das forças armadas simpáticos à vitória do Eixo que se opunham às demandas dos Aliados ${ }^{34}$. Exemplo disso foi uma das passeatas organizadas pela Aliança da Juventude Argentina - agrupação chefiada pelo general Juan Bautista Molina —, que em maio de 1943 levou dez mil nacionalistas a marchar no centro da cidade de Buenos Aires, brandindo as seguintes palavras de ordem: "Morte aos porcos britânicos", Morte aos judeus", "Viva Castilho e a neutralidade" ${ }^{35}$. 
Apesar de manifestarem-se em favor da neutralidade argentina diante da guerra, o fato é que os nacionalistas não esconderam em nenhum momento o desejo pela vitória do Eixo. Como os próprios nacionalistas de direita reconheciam com orgulho, possuíam uma posição no mínimo filofascista e se consideravam os defensores austrais da causa da extrema direita européia, e em especial das tradições latinas e da Espanha imperial e católica:

Nós, herdeiros da Espanha e de Roma, estamos colocados aqui no extremo do mundo austral para guardar o flanco da Europa e nossa missão consiste em reproduzir a imagem familiar da nossa estirpe. (...) Estamos com a Europa, somos a Europa renascendo nas novas terras da esperança; suas lutas, suas dores, as vivemos em toda sua intensidade e em todo seu teológico sentido. (...) 0 movimento e a crise do mundo, (...) deparam, pois, a Argentina, diante de uma vasta e dolorosa empresa de recuperação e reconquista, (...) pela forma como a Reconquista nacional coincide com a da Revolução do mundo ${ }^{36}$.

0 proselitismo nacionalista viu-se recompensado com a atitude dos militares do exército, que em junho de 1943 realizaram um golpe militar que derrubou o presidente Ramón Castillo. 0 golpe foi liderado pela logia "Grupo Obra e 314 Unificação" (GOU), integrada por coronéis, e no novo regime político que se abriu rapidamente configurou-se a hegemonia do segmento militar simpático à causa do Eixo, o que no plano interno traduziu-se na manutenção da posição neutra da Argentina perante a Segunda Guerra. Tal posição era vantajosa na perspectiva de certos setores castrenses ao viabilizar ao mesmo tempo o comércio com seu principal parceiro comercial e importador, a Grã-Bretanha ${ }^{37}$, e a cooperação econômica da Argentina com a Alemanha, cujo objetivo imediato era a modernização do complexo industrial-militar, e no futuro poderia significar uma aliança estratégica para o poderio argentino caso os Aliados fossem derrotados. Durante a sua breve vigência, até 1946, o regime militar buscou construir uma nova legitimidade política manifestando posições nacionalistas pela regeneração dos costumes na vida pública e pela instauração da justiça social. 0 coronel Juan Domingo Perón tornou-se a figura mais importante do novo sistema de poder, ao acumular as funções de vice-presidente, ministro da guerra e secretário de trabalho e previdência.

Embora não tivessem participado do golpe de 1943, os nacionalistas de direita o consideraram como algo que também lhes pertencia. Nos anos anteriores tinham reivindicado a sua realização para restaurar o frustrado governo nacionalista-militar do general Uriburu, prestando seu integral apoio ao novo regime. No plano interno, estavam dadas as condições para resistir à pressão dos Estados Unidos e de seus simpatizantes argentinos, bem como para proje- 
tar o país à condição de potência regional. Muitos nacionalistas participaram do novo regime ocupando relevantes funções, embora a cúpula militar temesse as repercussões das posições e ações dos nacionalistas mais extremados, pois podiam fortalecer a identificação do governo com o Eixo ${ }^{38}$. Os nacionalistas, por sua vez, temiam a política cada vez mais populista de aliança do governo com os sindicatos de trabalhadores, impulsionada pelo coronel Perón, bem como a possibilidade dos militares cederem às pressões norte-americanas no sentido da ruptura de relações com o Eixo.

Até quando foi possível, o regime militar sustentou a posição de neutralidade em presença da guerra, porém a manutenção dessa postura não foi favorecida pelo desenvolvimento do conflito bélico e das lutas políticas dentro da Argentina, onde a oposição pró-aliada fustigava de forma crescente o governo de fato. Acuado nos planos interno e externo, não restou outra opção ao governo argentino senão abrir mão de sua neutralidade, por meio da ruptura de relações com o Eixo em janeiro de 1944 e da declaração de guerra aos seus países em março de 1945. Os rumos da conjuntura internacional foram adversos às intenções dos nacionalistas argentinos. A capitulação do governo argentino à posição aliada foi repudiada pela maioria dos nacionalistas, mas de qualquer modo eles renovaram suas esperanças de grandeza nacional quando o coronel Perón se lançou candidato às eleições presidenciais de 1946. Por meio de uma coalizão que se revelaria bastante contraditória logo após o pleito e ao longo dos anos seguintes, Perón elegeu-se com o apoio de conservadores, nacionalistas de direita, de setores do movimento sindical, da igreja e da maioria dos setores populares. Durante o peronismo, os nacionalistas de direita receberam cargos importantes, sobretudo vinculados à área cultural e educacional. Não puderam assistir à expansão territorial da Argentina, mas muitos deles acreditaram que a "Grande Argentina" estava se tornando uma realidade graças à liderança de Perón, homem forte que julgavam emular os dons dos antigos caudilhos argentinos. 


\section{FRONTEIRAS E REABILITAÇ̃̃O DA NACIONALIDADE}

Qualquer análise a respeito dos sonhos nacionalistas de construção da "Grande Argentina” não pode ignorar o papel desempenhado pela revisão da história levada a cabo pelos intelectuais de direita. Eles desenvolveram uma interpretação histórica segundo a qual a Argentina vivia um processo de decadência em virtude da pressão de um conjunto de forças inimigas da nação, em atividade desde o período da independência política. A aliança dos agentes internos e externos do liberalismo teriam usurpado a soberania argentina, levando à perda de territórios, à adoção de um modelo político forâneo - o liberalismo - e à dependência econômica com relação à Grã-Bretanha. Esta foi uma das principais explicações do "revisionismo histórico", movimento de interpretação do passado nacional, organizado para contrapor-se à chamada "história oficial", baseada na perspectiva liberal. Para os nacionalistas, a versão liberal não passava de uma falsificação, revelando apenas o ponto de vista dos vencedores políticos no século XX, em favor de minorias e interesses que na essência seriam antiargentinos ${ }^{39}$.

O decadentismo foi um componente essencial da interpretação revisionista. Como mencionamos anteriormente, o decadentismo foi assimilado pelos argentinos de um conjunto de autores europeus e adaptado às circunstâncias argentinas. Os revisionistas projetaram na Idade Média um modelo ideal de civilização, e viram a derrocada dessa era como o início de um longo processo de decadência do Ocidente, ao qual se juntaria a Argentina no século XIX. A Argentina viria sofrendo o seu ciclo de decadência a partir da queda do governador da Província de Buenos Aires, Juan Manuel de Rosas, na Batalha de Caseros, em 1852, que significou a derrota do federalismo e a implantação de um modelo político e econômico liberal fortemente vinculado à Grã-Bretanha. A era de Rosas foi convertida pelos revisionistas na "idade de outro" da história argentina, que continuava, num plano mais elevado, as tradições da época colonial ${ }^{40}$.

A interpretação revisionista fornecia a chave para que os intelectuais nacionalistas explicassem a natureza da crise argentina, denunciassem os seus responsáveis e justificassem as alternativas necessárias para recolocar a nação na verdadeira trilha que a conduziria ao engrandecimento. 0 receituário revisionista para os problemas nacionais passava pela condução de um "caudilho moderno" ao poder, pela restauração dos valores do passado medieval e colonial, pela retomada da tradição hispânica e pela reincorporação dos territórios que antigamente integravam o vice-reinado do Rio da Prata, isto é, Bolívia, Paraguai e Uruguai..

Para os nacionalistas, os argentinos tinham perdido a consciência geográfica da nação, atributo específico das nações fortes e primeiro degrau para a sua 
“ascensão imperial”. Pensavam que o sentimento patriótico deveria assentar-se principalmente em bases territoriais. Em vista disso, o círculo da revista Nueva Política teve como um dos temas prioritários a história das fronteiras argentinas e as perspectivas que o presente desenhava para a sua ampliação $0^{41}$. Uma seção denominada "Fronteiras" foi dedicada na revista para sensibilizar os leitores em relação à importância da geografia na história da nação argentina. Numa matéria, o vice-reinado do Rio da Prata era definido como o auge do esplendor da nação nos seguintes termos:

(...) a história das nossas fronteiras é a história da desintegração do antigo ViceReinado do Rio da Prata. Nossos antepassados durante século e meio de luta tenaz e perseverante, de progressiva expansão civilizadora criaram o contorno daquela unidade geográfica e racial, moral e nacional, que em 1776 alcançou a máxima categoria hierárquica e administrativa ${ }^{42}$.

Segundo a interpretação nacionalista, os agentes do liberalismo eram os grandes responsáveis pela diminuição territorial da nação, pelo que eles e o liberalismo eram responsabilizados de traição. Contra isso, dever-se-ia restaurar as antigas tradições hispânicas e católicas vilipendiadas pelo liberalismo e pelo materialismo. De acordo com Ernesto Palácio,

Nossa verdadeira tradição, nossa história, é a da Espanha, por meio dos conquistadores, que continuam vivendo em nós. ${ }^{43}$

A visão revisionista buscava afirmar uma outra matriz de identidade nacional em oposição àquela desenvolvida pela tradição liberal argentina. Tratava-se, na verdade, de substituir uma concepção política de nação por outra de base cultural, acompanhando dessa forma a guinada dos movimentos de direita europeus a partir de fins do século XIX ${ }^{44}$. Para a direita nacionalista argentina, a nação nada tinha que ver com cidadãos dotados de soberania política, conforme a fórmula consagrada pela Revolução Francesa. No lugar disso, a Argentina era compreendida como uma entidade constituída por tradições, história, língua e religião, cuja verdadeira face tinha sido renegada e ocultada dos argentinos pela ordem liberal implantada após a derrota dos caudilhos federais na segunda metade do século XIX.

Com orgulho, os nacionalistas consideravam a Argentina como o mais fiel representante da tradição latina, hispânica e católica na América Latina. A Argentina não era portanto um país novo como se afirmava correntemente, mas uma nação de antigas raízes, fiel à "raça" ${ }^{45}$ espanhola, que contava com quatro séculos em terras das "Índias” e doze séculos de cultura católica na Espanha Em outros termos, afirmava-se uma concepção de nação segundo a qual a Ar- 
gentina era concebida como herdeira americana de um país de vocação imperial, católica e reacionária. Diante da crise mundial, os nacionalistas apostavam que seu país estava destinado a cumprir no futuro a mesma trajetória gloriosa que outrora a Espanha percorrera, tornando realidade o sonho da "Grande Argentina”. Acrescente-se ainda que a reivindicação da filiação à Espanha no contexto do regime franquista não era casual, mas sobretudo reforçava a identidade autoritária que os nacionalistas argentinos conferiam ao seu próprio país.

0 revisionismo histórico foi um caso exemplar de instrumentalização do conhecimento histórico por agentes que perseguiam certos fins políticos. Para os nacionalistas isso não era problema, pois compartilhavam de maneira consciente da visão de Charles Maurras, o líder da Ação Francesa, para o qual a disciplina histórica deve julgar para que se possa agir. Nessa perspectiva, a disciplina histórica não serviria para nada se não oferecesse lições e exemplos que o historiador deveria selecionar para orientar as ações no presente. Como os nacionalistas acreditavam que a verdade estava do seu lado, tratava-se apenas de buscar a sua comprovação no passado.

Certas análises têm questionado a originalidade das idéias dessa direita, sob o argumento de que elas foram copiadas das correntes européias. Em relação ao expansionismo territorial, embora ele tenha sido objeto do fascismo na Europa, a sua defesa pelos nacionalistas argentinos não pode ser explicada como simples mimetismo ideológico, o que seria incorrer em grave reducionismo. Essa nova direita formou-se e atuou num ambiente intelectual nacional atravessado por tradições culturais e lutas ideológicas que condicionaram o teor do seu ideário. Ao apropriar-se de certos aspectos da ideologia da extrema direita européia, os nacionalistas argentinos o fizeram respondendo a questões da política nacional e internacional. Não se deve perder de vista que as possibilidades de sucesso do projeto imperialista eram bastante plausíveis, estando condicionadas à vitória do Eixo na Segunda Guerra.

Além disso, os nacionalistas elaboraram um conjunto de representações e de explicações históricas específicas a respeito do seu país que podiam servir para defender o imperialismo argentino. 0 ponto de partida dos nacionalistas residiu na crítica àqueles aspectos do passado e do presente da Argentina, que supostamente tinham conduzido o país à decadência e instaurado a corrupção de todos os valores pátrios. Dispondo de capital político limitado, tais regeneradores da nação transformaram a pena numa das suas mais importantes armas e sintetizaram no revisionismo histórico a explicação para os infortúnios do país. Dessa forma, obtiveram uma duradoura justificação baseada no passado para a valorização das forças armadas, dos regimes fortes e da ascensão da Argentina a potência econômica e militar, com direitos de expansão sobre os seus vizinhos. 


\section{NOTAS}

* Esta é uma versão modificada de trabalho apresentado no seminário internacional "Procesos de Integración y Bloques Regionales. Historia, Economia y Política”, realizado na Universidade de Buenos Aires, entre 10 e 12 de setembro de 1997.

** Doutor em História e docente do Departamento de História da Faculdade de Ciências e Letras. Universidade Estadual Paulista - Campus de Assis.

${ }^{1}$ Designo por cultura política o conjunto de atitudes, crenças, normas e valores comuns a um determinado universo populacional.

${ }^{2}$ ALVAREZ, Enrique Zuleta. El Nacionalismo Argentino. 2 vols. Buenos Aires: La Bastilla, 1975.

${ }^{3}$ BUCHRUCKER, Cristián. Nacionalismo y Peronismo. La Argentina en la Crisis Ideológica Mundial (1927 - 1955). Buenos Aires: Sudamericana, 1987, p. 232.

${ }^{4}$ ROCK, David. La Argentina Autoritária. Los Nacionalistas, su Historia y su Influencia en la Vida Pública. Buenos Aires: Ariel, 1993, p. 143.

${ }^{5}$ Empregamos o conceito de ideologia como "visão de mundo" que objetiva assinalar o significado das práticas coletivas e das representações, bem como o modelo de sociedade legítima para os nacionalistas. Entendemos a ideologia como um artefato simbólico que unifica os homens em torno de certas aspirações, sentimentos e idéias, conferindo identidade a um grupo que se opõe a outros. Embora utilizemos ideologia no singular para designar o conjunto de representações da direita nacionalista, deve-se ter claro que as diferenças entre os seus agentes se traduziram na produção de representações nem sempre coincidentes, embora sempre filiadas a um núcleo comum de idéias que conferia unidade a esse espectro ideológico. A nossa ênfase na dimensão ideológica justifica-se, uma vez que os nacionalistas travaram seus principais embates no plano simbólico de modo a impor socialmente as suas concepções e a exercer domínio em relação a certos grupos sociais e no campo político. Cf. ANSART, Pierre. Ideologias, conflitos e poder. Rio de Janeiro: Zahar, 1978, p. 36; CHARTIER, Roger. A História Cultural. Entre Práticas e Representações. Lisboa: Difel, 1990, p. 47.

${ }^{6}$ Esse político foi eleito à presidência pela primeira vez em 1916, sob os auspícios da Lei Saénz Peña, que instaurou o voto masculino secreto. Na segunda gestão enfrentou uma intensa oposição agravada com a crise de 1929, que incluiu trabalhadores e principalmente setores da burguesia, da classe média e militares.

${ }^{7}$ Algumas das principais organizações foram: Legión Cívica Argentina, Acción Nacionalista Argentina-Afirmación de una Nueva Argentina, Legión de Mayo, Guardia Argentina, Amigos de Crisol, Unión Nacional de Estudiantes Secundarios-Alianza de la Juventud Nacionalista, Restauración, Afirmación Argentina, Frente de Fuerzas Fascistas-Unión Nacional Fascista e Renovación. Em relação às publicações, destacavam-se os seguintes jornais e revistas: Crisol, Bandera Argentina, Nueva Política, Nuevo Orden, La Voz del Plata, El Pampero, Sol y Luna e Cabildo.

${ }^{8}$ Sobre o ideário da direita nacionalista argentina ver: BEIRED, José Luis Bendicho. Sob o Signo da Nova Ordem: Intelectuais Autoritários no Brasil e na Argentina (1914 - 1945). São Paulo: Loyola, 1999; ROCK, David. op. cit.; BUCHRUCKER, Cristián. op. cit.; GERSASSI, Marisa Navarro. Los Nacionalistas. Buenos Aires: Peña Lillo, 1968.

${ }^{9}$ Cf. BOURDIEU, Pierre. O poder simbólico. Lisboa: Difel, 1989. 
${ }^{10}$ Cf. BEIRED, José Luis Bendicho. op. cit., p. 267; SPENGLER, Oswald. La Decadencia de Occidente. Bosquejo de una Morfologia de la Historia Universal. 2 v., 10 ${ }^{\mathrm{a}}$ ed., Madrid: Espasa-Calpe, 1958, e BERDIAEFF, Nicolai. Un Nouveau Moyen Age. Paris: Plon, 1930.

${ }^{11}$ Organização criada em 1929 por intelectuais da direita nacionalista - Leopoldo Lugones, Rodolfo Irazusta, Roberto de Laferrère, Juan Carulla e Federico Ibarguren — com vistas a combater o governo de Hipólito Yrigoyen.

${ }^{12}$ CERDEIRA, Omar et alii. La Legión Cívica Argentina (1931 - 1932). Buenos Aires: Centro Editor de América Latina, 1989, p. 21. A Legião existiu até 1936.

${ }^{13}$ BUCHRUCKER, Cristián. op. cit., p. 210; POTASH, Robert. El Ejercito y la Política en la Argentina (I). 1928 - 1945. De Yrigoyen a Perón.. Buenos Aires: Hyspamérica, 1986; IBARGUREN, Federico. Orígenes del Nacionalismo Argentino. 1927-1937. Buenos Aires: Celsius, 1970.

${ }^{14}$ BEIRED, José Luis Bendicho. op. cit., p. 96.

${ }^{15}$ LUGONES, Leopoldo. "El Discurso de Ayacucho". In LUGONES, Leopoldo. Antología de la Prosa. (Sel. y coment. de Leopoldo Lugones h). Buenos Aires: Centurión, 1949, pp. 460-461. Ainda segundo o autor, tal qual na guerra, para a sociedade de cada país também valia essa metáfora emprestada da biologia, de modo que somente os mais aptos deveriam participar das responsabilidades governamentais. Os grifos constam desta edição.

${ }^{16}$ IRAZUSTA, Rodolfo. "La Revolución Americana”. In La Nueva Republica. 8/11/1930, apud IRAZUSTA, Júlio. (org). El Pensamiento Político Nacionalista - 2. Buenos Aires: Obligado, 1975, pp. 126-127.

${ }^{17}$ Retomaremos a questão do revisionismo histórico mais adiante.

${ }^{18}$ Durante essa década escreveu editoriais não assinados em La Nación. LUGONES FILHO, Leopoldo. "Información Preparatoria". In LUGONES, Leopoldo. La Grande Argentina. Buenos Aires: Huemul, 1962, p. 14.

${ }^{19}$ Idem, pp. 32-33.

${ }^{20}$ Idem, pp. 134-135.

${ }^{21}$ IRAZUSTA, Rodolfo \& Julio. La Argentina y el Imperialismo Británico. Buenos Aires: Ediciones Argentinas Condor, 1934.

${ }^{22}$ IRAZUSTA, Julio. “Las condiciones Internacionales del Nuevo Orden”. InNuevo Orden, 22/8/1940, p. 2.

${ }^{23}$ Nuevo Orden, "Las Bases de un Programa Nacionalista”, 22/4/1942, p.5, apud ALVAREZ, Enrique Zuleta. El Nacionalismo Argentino — 2. Buenos Aires: La Bastilla, 1975, pp. 835-836.

${ }^{24}$ RAPOPORT, Mário. Gran Bretaña, Estados Unidos y las Clases Dirigentes Argentinas. 1940 1945. Buenos Aires: Belgrano, 1983, pp. 58-59.

${ }^{25}$ A respeito das pressões dos Estados Unidos e as tensões entre a Argentina e o Brasil ver BANDEIRA, L. A. Moniz. Estado Nacional e Política Internacional na América Latina. O Continente nas Relações Argentina-Brasil (1930 -1992). São Paulo: Ensaio, 1993, pp. 31-42.

${ }^{26}$ LUGONES, L. La Grande Argentina.. Buenos Aires: Huemul, 1962, pp. 32-34.

${ }^{27}$ LAS CASAS, Alvaro de. "Relaciones entre la Nación y el Estado". In Nueva Política, no 24, agosto de 1942, p. 27. 
${ }^{28}$ SORONDO, Marcelo Sanchez. "Politica Internacional”. [Editorial]. In Nueva Política, $\mathrm{n}$ ํ 18, diciembre de 1941, pp. 7-8.

${ }^{29}$ BERNARD0, Hector. "Nuestra Politica y el Brasil”. In Nueva Política, no 25, octubre de 1942, p. 24.

${ }^{30}$ BECU, Ricardo Zorraquin. "Sentido Actual del Virreinato". In Nueva Política, no 1, junio 1940, pp. $10-13$.

${ }^{31}$ Idem, p. 28.

${ }^{32}$ SORONDO, Marcelo Sanchez. "Buenos Aires, Cabeza del Sexto Continente”. In Nueva Política, nº 19, febrero 1942, pp. 3-4.

${ }^{33}$ RAPOPORT, Mário. Aliados o Neutrales? La Argentina Frente a la Segunda Guerra Mundial. Buenos Aires: Eudeba, 1988, pp. 16-17.

${ }^{34}$ LLAMBIAS, Héctor. "La Guerra Actual. La Posición Argentina”. In Nueva Política, nº 1, junio 1940, pp. 6-9. Já em 1928, Rodolfo Irazusta opunha-se à ingerência norte-americana na América Latina, afirmava a superioridade da "raça espanhola", propunha a dissolução da União Pan-americana, o abandono da Sociedade das Nações, e sugeria a convocação em Buenos Aires de uma assembléia dos países americanos irmãos. Ver: IRAZUSTA, Rodolfo. "Nicarágua". In "La Nueva República”, 15/1/1928, apud IRAZUSTA, Julio. (Selec. y Notas). Pensamiento Político Nacionalista - I. Buenos Aires: Obligado, 1975, pp. 52-54.

${ }^{35}$ ROCK, David. Op. cit., p. 144.

${ }^{36}$ SORONDO, Marcelo Sanchez. "Editorial". In Nueva Política, nº 11, abril de 1941, p. 4; SORONDO, Marcelo Sanchez. "Editorial”. In Nueva Política, n 3, agosto de 1940, p. 5.

${ }^{37}$ Embora contrariasse a política pan-americanista dos Estados Unidos, a neutralidade Argentina interessou sobremaneira ao governo britânico por garantir o fluxo de importação de alimentos argentinos durante o conflito bélico.

${ }^{38}$ Vale registrar que a cúpula militar que passou a dirigir o país não era unânime em relação à Segunda Guerra, dividindo-se entre os simpatizantes do Eixo e dos Aliados.

${ }^{39}$ Sobre o revisionismo histórico argentino ver: GERASSI, Marisa Navarro. op. cit., pp. 131-145; QUATTOCCHI-WOISSON, Diana. Los Males de la Memoria.. Buenos Aires: Emecé, 1995; PLÁ, Alberto. Ideologia y Método en la Historiografia Argentina.. Buenos Aires: Nueva Visión, 1972. A concepção decadentista da história foi analisada especialmente por DONGHI, Tulio Halperin. "El Revisionismo Histórico Argentino como Visión Decadentista de la Historia Nacional”. In Punto de Vista. Buenos Aires, no 23, 1985, pp. 13-14.

${ }^{40}$ Em 1938, os nacionalistas fundaram o Instituto de Investigações Históricas Juan Manuel de Rosas em Buenos Aires, que se consagrou como "lugar de memória" de oposição à Academia Nacional de História, instituição esta que na visão dos nacionalistas zelava pela memória histórica oficial, isto é, liberal.

${ }^{41}$ BECU, Ricardo Zorraquin. "Sentido Actual del Virreinato". In Nueva Política, no 1, junio 1940, pp. 10-13.

${ }_{42}$ "Fronteras". In Nueva Política, no 8, enero 1941, p. 18.

${ }^{43}$ PALÁCIO, Ernesto. La Historia Falsificada. Buenos Aires: Peña Lillo, 1960, p. 32. Editado origi- 
nalmente em 1939, este livro foi um dos marcos do revisionismo histórico. 0 seu título é mais do que representativo do enfoque a respeito da chamada história oficial.

${ }^{44}$ A propósito dessas matrizes do conceito de nação, ver GUERRERO, Andrés Blas. Nacionalismo e ideologías políticas contemporáneas. Madrid: Espasa-Calpe, 1984.

${ }^{45}$ Para os nacionalistas argentinos, o termo "raça" tinha uma conotação essencialmente cultural.

${ }^{46}$ QUESADA, H. Saenz y. “La Tradición Argentina”. In Nueva Política, nº 3, pp. 13-15. 